\title{
Analisis Peran Komunikasi Anggota Kelompok dalam Jaringan Komunikasi
}

\author{
E. Anggriyani \\ Politeknik ATK, Yogyakarta \\ Jl. Ateka, Bangunharjo, Sewon, Bantul, Yogyakarta \\ Email: emiliana.anggry@gmail.com \\ emilia_anggri@kemenperin.go.id
}

\begin{abstract}
ABSTRAK
Penelitian ini bertujuan untuk menganalisis peran komunikasi anggota kelompok dalam jaringan komunikasi. Materi yang digunakan dalam penelitian ini adalah semua anggota kelompok sapi potong yakni Kelompok Sido Rejo dan Kelompok Sido Mulyo di Kabupaten Bantul yang pernah memperoleh informasi mengenai inovasi kompos. Metode pengambilan data dilakukan dengan sensus melalui wawancara kepada peternak. Peran komunikasi anggota kelompok dianalisis secara deskriptif dengan metode sosiogram. Hasil penelitian menunjukkan bahwa kedua kelompok memiliki satu klik dengan opinion leader ketua kelompok masing-masing. Kesimpulan dari penelitian ini adalah ketua kelompok masih menjadi arah utama dalam penyebaran informasi dalam hal ini sebagai opinion leader.
\end{abstract}

Kata kunci: peran komunikasi, jaringan komunikasi, kelompok.

\section{Analyze The Influence of Farmers'Affection on Adoption of Innovation}

\begin{abstract}
The aim of this study was to analyze the influence of farmers' affection on adoption of innovation. The respondents used in this study were the members of Sido Rejo and Sido Mulyo groups in Bantul who had already obtained information about the innovation of compost. This research was conducted census through interviews of the object of research to obtain primary data. The influence of farmers' affection on adoption of innovation was analyzed descriptively with sosiogram method. The results showed that both groups have one click with opinion leaders of each group leader. The conclusion of this study is the leader of the group is still the main direction in the dissemination of information in this regard as opinion leaders.
\end{abstract}

Keywords: the role of communication, communication networks, groups.

\section{PENDAHULUAN}

Pupuk organik merupakan pupuk yang dapat dijadikan alternatif selain penggunaan pupuk kimia. Pupuk organik dibuat salah satunya dari kotoran ternak. Ternak yang semakin berkembang maka semakin tinggi pula limbah yang dihasilkan dari ternak khususnya kotoran sapi potong (feses). Sebagian peternak membiarkan kotoran sapi potong hanya ditumpuk atau dibiarkan saja. Kotoran yang tidak diolah dan langsung digunakan untuk memupuk tanaman akan sangat berbahaya dan dapat meracuni tanaman. Kotoran yang tidak diolah tersebut menghasilkan panas yang merupakan hasil perombakan bahan organik dan dihasilkan asam organik yang beracun yang dapat menghambat pertumbuhan tanaman. Oleh karena itu kotoran sapi potong akan lebih baik apabila diolah dahulu menjadi kompos. Kotoran yang telah diolah menjadi kompos, unsur hara dapat dimanfaatkan oleh tanaman, disamping itu panas dan racun telah hilang selama proses pengomposan.

Kajian komunikasi pertanian dan pembangunan dalam bidang pertanian perlu 
mendapat tempat tersendiri. Komunikasi pertanian adalah suatu pernyataan antar manusia yang berkaitan dengan kegiatan di bidang pertanian, baik secara perorangan atau berkelompok yang sifatnya umum menggunakan lambang-lambang tertentu (Soekartawi, 2005).

Komunikasi pertanian dalam penggunaannya untuk bidang penyuluhan sangat penting guna menunjang penyerapan informasi dari penyuluh, sehingga pesan yang disampaikan penyuluh dapat diterima dan diterapkan dengan baik dan benar. Akan tetapi yang terjadi saat ini tidak semua teknologi baru yang ditawarkan oleh pihak penyuluh mampu diserap dan diadopsi oleh peternak. Van Den Ban (1999) menyatakan tujuan utama kebijakan pembangunan pertanian yakni merangsang petani untuk memanfaatkan teknologi produksi modern dan ilmiah yang dikembangkan melalui penelitian.

Responden diminta untuk melihat ke belakang dan merekonstruksi sejarah masa lalunya pada pengalaman inovasi. Kemampuan melihat ke belakang tidak begitu akurat dan pasti bervariasi seperti (1) arti penting inovasi bagi responden, (2) panjang waktu untuk recall, (3) perbedaan individu dalam hal pendidikan dan kemampuan mental (Rogers, 1976).

Proses adopsi dilanjutkan dengan penyebaran atau difusi kepada anggota sistem yang lain. Proses penyebaran ini tentunya membutuhkan seorang opinion leader yang mampu membantu dalam penyebaran inovasi yang tergambar dalam suatu jaringan komunikasi. Setiap peternak dengan latar belakang yang berbeda-beda juga memiliki preferensi sumber informasi yang berbeda-beda dalam memperoleh inovasi. Berbagai macam sumber informasi pertanian tersedia diantaranya yaitu melalui majalah pertanian, televisi, radio, hasil penelitian dan sumber personal. Akan tetapi karena minimnya akses peternak dan kurangnya publikasi ke masyarakat maka hanya sedikit sumber informasi yang mampu diakses peternak.
Inovasi mengenai pengolahan kotoran ternak dengan pembuatan kompos telah diperkenalkan di kelompok peternak di Kabupaten Bantul, terlebih adanya peraturan dari Pemerintah Daerah Bantul bahwa kotoran ternak sebaiknya diolah lebih lanjut, digunakan untuk memupuk/memperbaiki lahan di Bantul daripada di jual ke luar daerah. Hal tersebut dimaksudkan untuk memperbaiki lahan pertanian dan meningkatkan sistem pertanian organik di daerah Bantul. Program yang dicanangkan tersebut tidak sepenuhnya berjalan, banyak peternak tidak menerapkan pengolahan kotoran ternak tersebut. Oleh karena itu penelitian ini bermaksud untuk menjawab pertanyaan bagaimanakah peran komunikasi anggota kelompok di dalam jaringan komunikasi.

Tujuan dari dilaksanakannya penelitian ini yaitu menganalisis peran komunikasi anggota kelompok dalam jaringan komunikasi.

Penelitian ini diharapkan bermanfaat sebagai pertimbangan dalam penentuan kebijakan pemerintah yang berkaitan dengan strategi penyuluhan pertanian khususnya dalam bidang peternakan. Jaringan komunikasi yang terjadi dapat digunakan sebagai acuan untuk mempercepat proses difusi. Bagi penyuluh dan pihak terkait agar mampu memberikan sumber informasi inovasi yang sesuai dengan kebutuhan peternak.

\section{MATERI DAN METODE}

\section{Lokasi dan Materi Penelitian}

Penelitian ini dilaksanakan pada kelompok peternak sapi potong Kelompok Sido Rejo, Patalan, Jetis, Bantul dan Kelompok Sido Mulyo, Segoroyoso, Pleret, Bantul. Penelitian ini dilakukan pada Bulan September sampai November 2011. Sumber informasi berasal dari peternak kedua kelompok tersebut. Pengumpulan data primer dilakukan dengan alat bantu kuesioner. 


\section{Metode}

\section{Penentuan responden}

Penentuan responden penelitian dengan metode sensus yaitu mengambil semua anggota Kelompok Sido Rejo dan Sido Mulyo di Kabupaten Bantul untuk menggambarkan masing-masing sistem kelompok peternak. Kedua kelompok tersebut dipilih karena berdiri pada tahun yang berbeda sehingga tergolong kelompok yang relatif lama (18 tahun) dan baru (7 tahun), serta pernah mendapat informasi mengenai inovasi pembuatan kompos dari pihak penyuluh atau pihak luar baik secara penjelasan maupun demonstrasi teknis.

\section{Macam data dan proses pengambilan data}

Data primer diperoleh langsung dari peternak melalui wawancara terstruktur dengan menggunakan kuisioner dan pengamatan langsung. Data yang diambil meliputi identitas responden, pengalaman beternak, lama menjadi anggota kelompok, tingkat kosmopolitan, sumber informasi personal dan non personal, pengetahuan peternak tentang pembuatan kompos, afeksi peternak tentang pembuatan kompos, adopsi inovasi kompos dan peran komunikasi anggota kelompok. Data sekunder diperoleh dari Dinas Pertanian Kabupaten Bantul dan dinas terkait.

\section{Pengukuran variabel}

Peran anggota kelompok dalam jaringan komunikasi dilakukan dengan melihat frekuensi responden sebagai sumber informasi dan tujuan reponden dalam mencari sumber informasi. Hal ini dilihat dalam analisis sosiogram secara deskriptif.

\section{Batasan Operasional}

Beberapa variabel dalam penelitian ini dapat dijelaskan sebagai berikut :

1. Difusi inovasi kompos adalah proses penyebaran penggunaan inovasi kompos melalui saluran personal maupun non personal selama waktu penelitian yang diperkenalkan dalam satu sistem kelompok peternak.

2. Inovasi kompos merupakan gagasan, cara, tindakan mengenai pengolahan kotoran ternak menjadi kompos.

3. Umur peternak (tahun) adalah usia peternak yang dihitung dari sejak lahir sampai saat dilakukan wawancara.

4. Pendidikan peternak adalah lama pendidikan formal yang pernah ditempuh. Skor pendidikan dibagi menjadi :

a. Lebih dari atau sama dengan wajib belajar 9 tahun (setara SMP) = skor 2 .

b. Kurang dari wajib belajar 9 tahun $=$ skor 1.

5. Kosmopolitan merupakan tingkat keterbukaan petani dalam memperoleh informasi baik personal maupun non personal dengan indikatornya adalah frekuensi perjalanan/pergi keluar daerah dan jumlah kepemilikan media massa, dengan rincian skor sebagai berikut :

a. Keluar daerah (dalam satu bulan terakhir)

1) Lebih dari $3 \mathrm{kali} / \mathrm{minggu}=$ skor 2

2) 1 sampai $3 \mathrm{kali} / \mathrm{minggu}=$ skor 1

3) Tidak pernah $=$ skor 0

b. Jumlah kepemilikan media massa
1) $>2$
$=$ skor 2
2) 1 sampai 2 = skor
3) Tidak punya $=$ skor 0

6. Pengalaman beternak sapi (tahun) adalah lama waktu peternak mulai dari pertama kali mengusahakan/memelihara sapi sampai dilakukan wawancara.

7. Lama menjadi anggota kelompok (tahun) adalah lama waktu dari awal masuk menjadi anggota kelompok peternak sampai dilakukan wawancara.

8. Jaringan komunikasi adalah saluran yang digunakan untuk menerima dan meneruskan pesan dari satu orang ke orang lain dalam satu kelompok peternak.

9. Opinion leader adalah kedudukan anggota kelompok peternak dalam jaringan komunikasi yang ditunjukkan dengan jumlah paling banyak dari anggota lain yang memilihnya sebagai pasangan komunikasi.

10. Klik adalah anggota-anggota dari sistem (kelompok) yang relatif lebih sering 
berinteraksi satu sama lain dibandingkan dengan anggota-anggota lainnya dalam sistem komunikasi yang sama.

11. Liaison adalah seorang anggota kelompok yang menghubungkan dua klik atau lebih dalam satu kelompok/sistem, namun ia tidak menjadi anggota klik manapun.

12. Bridge adalah seorang anggota kelompok yang menghubungkan dua klik atau lebih dalam satu kelompok/sistem dan ia menjadi anggota dari klik-klik tersebut.
13. Isolated adalah individu yang tidak menjadi anggota dalam klik dalam satu sistem atau individu yang tidak terlibat dalam dalam jaringan komunikasi.

14. Satuan unit ternak untuk sapi jantan dewasa senilai 1,0 UT, anak sapi yang berumur 0 sampai 1 tahun senilai 0,3 UT, sapi muda yang berumur 1 sampai 2 tahun senilai 0,6 UT, sapi muda yang berumur 2 sampai 3 tahun senilai 0,8 UT dan sapi muda yang berumur lebih dari 3 tahun senilai 1,0 UT (Gittinger, 1986).

\section{HASIL DAN PEMBAHASAN}

\section{Karakteristik Responden}

Tabel 1. Karakteristik Responden Kelompok Sido Rejo dan Sido Mulyo

\begin{tabular}{|c|c|c|c|c|}
\hline \multirow[t]{2}{*}{ No } & \multirow[t]{2}{*}{ Karakteristik responden } & \multicolumn{2}{|c|}{ Kelompok ternak } & \multirow[t]{2}{*}{ Probability } \\
\hline & & Sido Rejo & Sido Mulyo & \\
\hline 1 & Rata-rata umur (tahun) & $49,35 \pm 11,7$ & $46,63 \pm 12,58$ & 0,362 \\
\hline 2 & Tingkat pendidikan $(\%)$ & & & $0,003^{* *}$ \\
\hline & $<$ SMP & 41,37 & 68,33 & \\
\hline & SMP & 19,57 & 20 & \\
\hline & SMA & 21,74 & 11,67 & \\
\hline & $>$ SMA & 17,39 & 0 & \\
\hline 3 & Pekerjaan utama $(\%)$ & & & $0,046^{*}$ \\
\hline & Petani & 63,04 & 80 & \\
\hline & Bukan petani & 36,96 & 20 & \\
\hline 4 & Rata-rata pengalaman beternak (tahun) & $18,25 \pm 13,61$ & $23,15 \pm 15,73$ & 0,170 \\
\hline 5 & $\begin{array}{l}\text { Rata-rata lama menjadi anggota kelompok } \\
\text { (tahun) }\end{array}$ & $12,23 \pm 6,47$ & $5,72 \pm 0,88$ & $0,000^{*}$ \\
\hline 6 & Tingkat kosmopolitan $(\%)$ & & & 0,271 \\
\hline & Rendah & 93,48 & 98,33 & \\
\hline & Tinggi & 6,52 & 1,67 & \\
\hline 7 & Rata-rata luas lahan pertanian (ha) & $1,33 \pm 1,69$ & $0,26 \pm 0,45$ & $0,000^{* *}$ \\
\hline 8 & Rata-rata jumlah kepemilikan sapi (UT) & $1,31 \pm 0,79$ & $0,99 \pm 0,71$ & 0,198 \\
\hline
\end{tabular}

Responden merupakan peternak anggota pada Kelompok Sido Rejo, Patalan,
Kecamatan Jetis dan Kelompok Sido Mulyo, Segoroyoso, Kecamatan Pleret, Kabupaten 
Bantul masing-masing berjumlah 46 orang dan 60 orang. Karakteristik responden dalam penelitian ini meliputi umur, tingkat pendidikan, perkerjaan utama, pengalaman beternak, lama menjadi anggota kelompok, tingkat kosmopolitan, status sosial, rata-rata luas lahan pertanian yang dimiliki dan jumlah ternak yang dimiliki.

Tabel 1 menunjukkan bahwa terdapat perbedaan tingkat pendidikan, pekerjaan utama, lama menjadi anggota kelompok dan rata-rata luas lahan pertanian antara Kelompok Sido Rejo dengan Kelompok Sido Mulyo. Peternak Kelompok Sido Rejo memiliki pendidikan yang relatif lebih tinggi dari Kelompok Sido Mulyo. Pekerjaan utama sebagai petani di Kelompok Sido Mulyo lebih tinggi dari Kelompok Sido Rejo. Kepemilikan lahan pertanian di Kelompok Sido Rejo lebih luas dari Kelompok Sido Mulyo.

Rata-rata umur, rata-rata pengalaman beternak, tingkat kosmopolitan dan rata-rata kepemilikan jumlah ternak antara kedua kelompok tersebut tidak berbeda secara signifikan (Tabel 1).

\section{Analisis Peran Komunikasi Anggota Kelompok dalam Jaringan Komunikasi}

Peran anggota kelompok dalam jaringan komunikasi dibagi menjadi opinion leader, liasion, bridge dan isolated. Dalam rangka mengubah atau mendidik masyarakat seringkali diperlukan pengaruh dari tokohtokoh atau pemimpin masyarakat (community leaders) atau tokoh panutan (Sarwono, 2001).

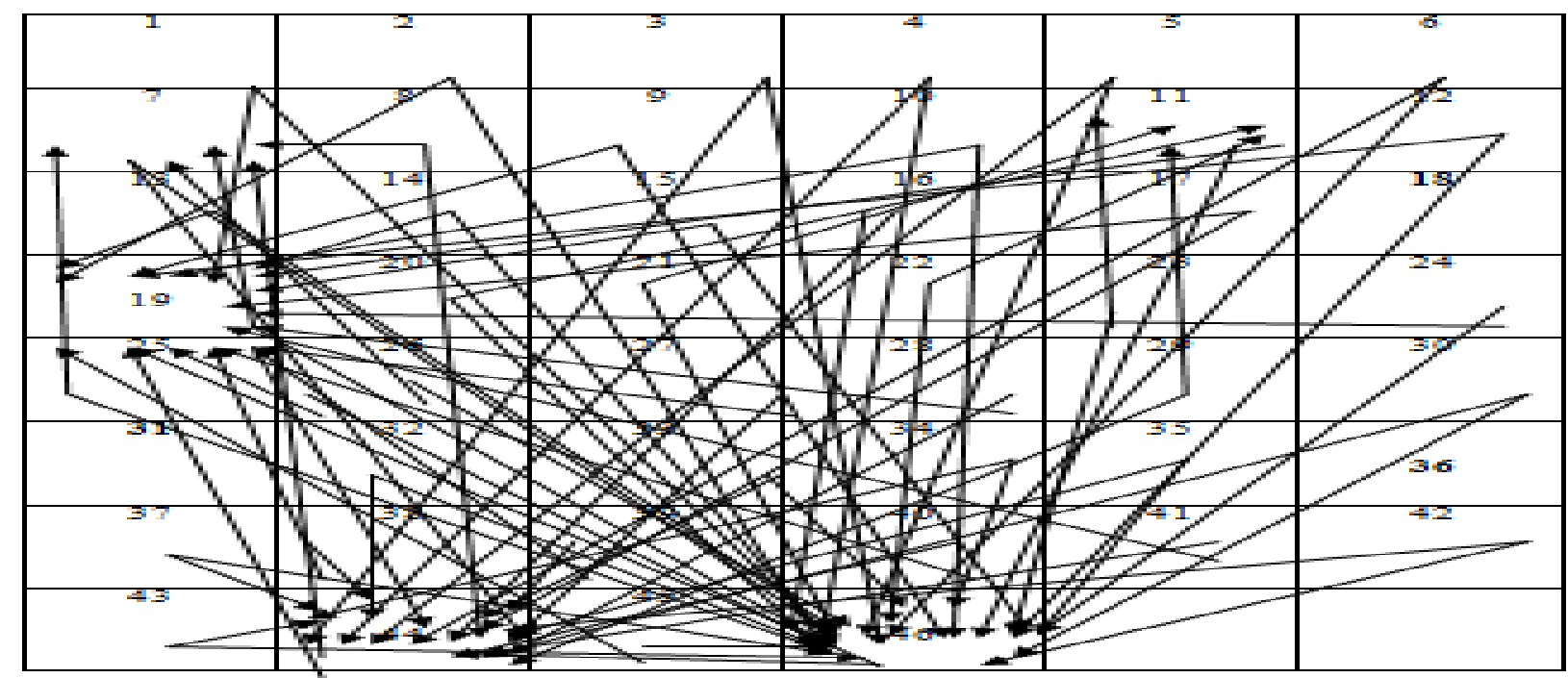

Gambar 1. Jaringan komunikasi Kelompok Sido Rejo

Gambar 1 terlihat bahwa tidak hanya 1 orang saja yang bisa dijadikan sebagai sumber informasi tetapi terdapat beberapa orang yang mampu dijadikan sebagai sumber informasi. Hal ini menunjukkan bahwa tingkat kemandirian kelompok ini cukup baik. Beberapa anggota kelompok memiliki pengetahuan yang memadai untuk dijadikan sebagai sumber informasi oleh anggota yang lain, tidak hanya ketua kelompok saja. Hal ini juga menunjukkan bahwa antar anggota-anggota kelompok relatif sering berinteraksi satu dengan yang lain sehingga kedekatan emosional dapat terjalin.

Peran anggota kelompok Sido Rejo dalam jaringan komunikasi untuk opinion leader adalah peternak nomor 46 yang juga 
berkedudukan sebagai ketua kelompok. Hal ini terlihat pada Gambar 1 dengan lebih banyaknya arah panah yang menuju peternak nomor 46 dibanding nomor yang lain. Hal tersebut sesuai dengan penelitian Rangkuti (2006) yang menyatakan bahwa petani yang berperan sebagai opinion leader dalam jaringan komunikasi petani dalam adopsi inovasi traktor tangan adalah ketua kelompok tani. Ketua juga mempunyai kegiatan usaha perdanganan beras lokal sehingga terdapat aktivitas informasi yang aktif yang ditunjukkan dengan arah panah yang cukup banyak.

Azwar (2004) menyatakan bahwa popularitas seorang subyek akan tampak dari banyaknya anggota kelompok yang memilih dirinya. Kepemimpinan selalu terkait dengan pengaruh dari satu atau beberapa individu yang merupakan minoritas terhadap keseluruhan kelompok atau mayoritas (Sarwono, 2001).

Bulu et al. (2009) menyatakan bahwa akses petani terhadap informasi inovasi jagung lebih tinggi pada sumber utama, namun frekuensi komunikasi inovasi antara petani dengan sesama petani lebih tinggi dibandingkan dengan tokoh masyarakat, sumber informasi utama, media cetak dan audio visual. Hal ini karena sebagian besar petani lebih sering berinteraksi dengan sesama petani karena kedekatan emosional dan hubungan sosial.

Analisis gambar sosiogram jaringan komunikasi di Kelompok Sido Rejo menunjukkan bahwa kelompok tersebut hanya memiliki satu klik sehingga tidak ada pihak yang bertindak sebagai liason dan bridge. Rangkuti (2006) menyatakan bahwa bridge merupakan pihak yang menjadi jembatan jaringan komunikasi dengan klik lain yang memungkinkan terjadinya diseminasi inovasi dengan sistem yang lebih luas. Liaison adalah individu yang menghubungkan dua klik yang berbeda tetapi dia tidak termasuk anggota dari dua klik tersebut yaitu anggota petugas dari PPL dan Dinas Pertanian Kabupaten Cianjur.

Pihak isolated pada Kelompok Sido Rejo adalah peternak nomor 18, 31 dan 36 . Ketiga orang peternak tersebut adalah pihak yang tidak mencai informasi keluar, tetapi lebih banyak menerima informasi saja. Ketiga orang ini cenderung pasif terhadap segala macam hal sehingga hanya menerima informasi yang ada, dan tidak berusaha mencari lebih lanjut mengenai hal yang telah didapat.

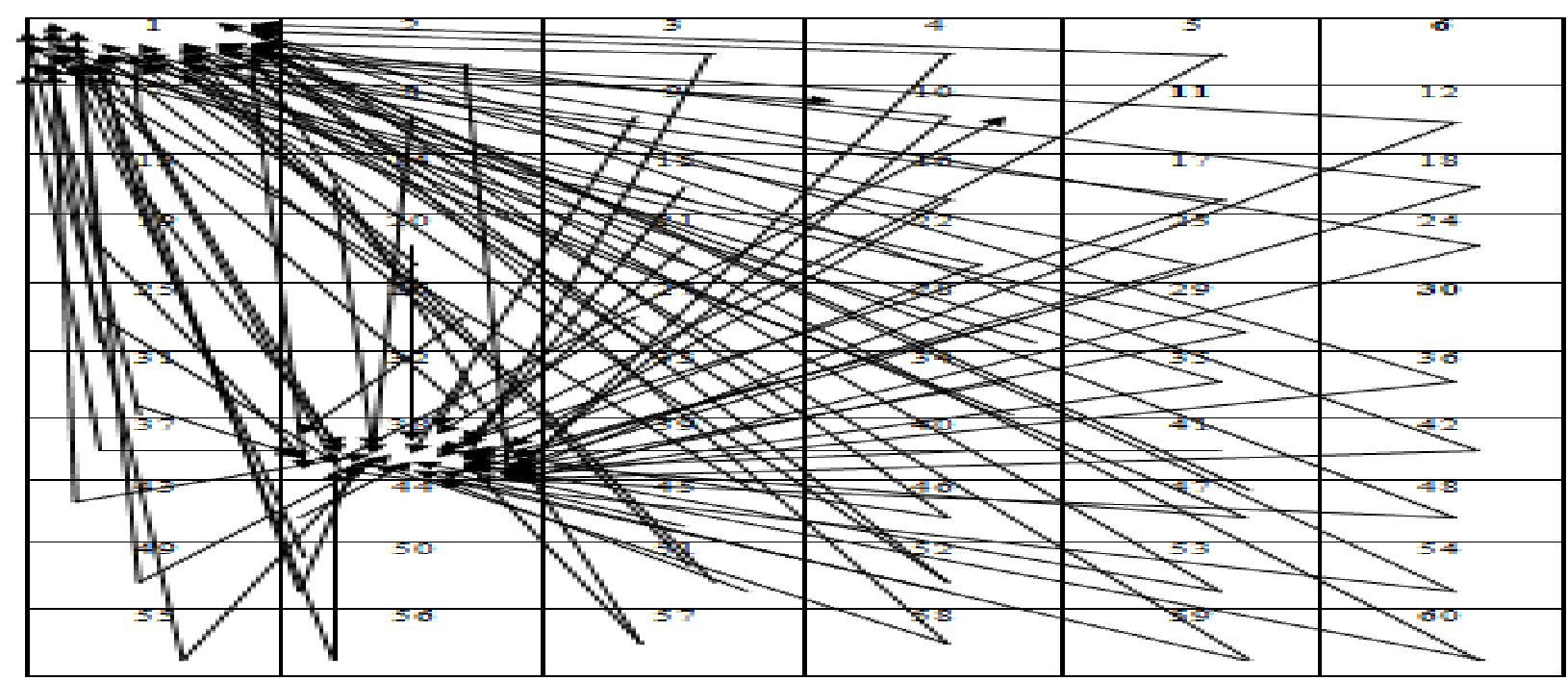

Gambar 2. Jaringan komunikasi Kelompok Sido Mulyo 
Gambar sosiogram jaringan komunikasi Kelompok Sido Mulyo pada Gambar 2 memiliki opinion leader peternak nomor 38 yang juga sebagai ketua kelompok. Muhammad (2009) menyatakan orang yang bertindak sebagai pengantara memegang posisi atau status yang lebih tinggi dari orang-orang lain dan merupakan wakil yang kuat dalam struktur kepemimpinan. Mereka terlibat lebih banyak dalam aktivitas komite daripada temannya dan menjadi anggota kelompok koordisasi pada tingkat yang lebih tinggi dalam organisasi.

Opinion leader adalah orang yang menjadi pemuka pendapat dalam suatu kelompok/sub kelompok. Opinion leader dalam jaringan komunikasi ditunjukkan dengan adanya individu yang mempunyai jumlah hubungan komunikasi lebih banyak daripada rata-rata jumlah hubungan komunikasi individu-individu lain dalam jaringan komunikasi, khususnya hubungan komunikasi yang mengarah pada individu tersebut (Hadi, 1999).

Gambar 2 terlihat bahwa hanya sedikit orang saja yang dituju sebagai sumber informasi yakni hanya beberapa pengurus saja. Sebagian besar anggota hanya memilih peternak nomor 1 dan nomor 38 sebagai sumber informasi. Keduanya merupakan pengurus, sehingga hal ini menunjukkan bahwa anggota-anggota hanya mencari informasi terbatas pada sebagian pengurus saja. Pengetahuan yang relatif memadai untuk dijadikan sebagai sumber informasi hanya beberapa orang saja yakni beberapa orang dari pengurus kelompok. Sebagian besar responden Kelompok Sido Mulyo masih memiliki pengetahuan yang rendah terutama pengetahuan terhadap inovasi. Hal tersebut menunjukkan mereka masih membutuhkan pihak luar/change agent/penyuluh dalam memberi berbagai informasi inovasi.

Kelompok ini hanya memiliki satu klik sehingga tidak memiliki pihak bridge dan liaison. Kelompok Sido Mulyo memiliki pihak isolated yaitu peternak nomor 6, 11 dan 30. Mereka adalah pihak yang tidak mencari informasi kemanapun juga dan tidak masuk dalam klik dalam satu sistem kelompok. Muhammad (2009) menyatakan isolate adalah anggota organisasi yang mempunyai kontak minimal dengan orang lain dalam organisasi. Orangorang ini menyembunyikan diri dalam organisasi atau diasingkan oleh temantemannya.

\section{KESIMPULAN}

Masing-masing sistem kelompok Sido Rejo dan Sido Mulyo memiliki satu klik dengan opinion leader oleh ketua kelompok masing-masing.

\section{DAFTAR PUSTAKA}

Azwar, S, M.A. 2004. Metode Penelitian. Pustaka Pelajar. Yogyakarta.

Bulu, Y.G., S.S. Hariadi, A.S. Herianto, Mudiyono. 2009. Pengaruh Modal Sosial dan Keterdedahan Informasi Inovasi terhadap Tingkat Adopsi Inovasi Jagung Di Kabupaten Lombok Timur Nusa Tenggara Barat. Jurnal Agro Ekonomi Volume 27 Nomor 1 (1-21). Balai Pengkajian Teknologi Pertanian NTB. Mataram.

Hadi, A.P. 1999. Analisis Jaringan Komunikasi Pada Kelompok Wanita Tani Mekarsari Kecamatan Dramaga Kabupaten Bogor. Bogor.

Muhammad, A. 2009. Komunikasi Organisasi. Bumi Aksara. Jakarta.

Rangkuti, P.A. 2006. Analisis Peran Jaringan Komunikasi Petani dalam Adopsi Inovasi Traktor Tangan Di Kabupaten Cianjur, Jawa Barat. Fakultas Teknologi Pertanian. Institut Pertanian Bogor. Bogor.

Rogers, E.M. 1976. New Product Adoption And Diffusion. Journal Of Consumers Research., Vol. 2, No. 4 (Mar., 1976), pp. 290-301.

Sarwono, S.W. 2001. Psikologi Sosial. Balai Pustaka. Jakarta.

Van Den Ban dan Hawkins. 1999. Penyuluhan Pertanian. Kanisius. Yogyakarta. 
